\title{
Tetraspan Protein CD151: A Common Target of Mood Stabilizing Drugs?
}

\author{
Len V. Hua, Ph.D., Marty Green, M.Sc., Adrienne Wong, Jerry J. Warsh, M.D., Ph.D.,
} and Peter P. Li, Ph.D.

The latency in onset of antimanic and mood stabilizing effects of lithium suggest that long-term neuronal adaptations mediated by changes in gene expression may be important to the therapeutic action of lithium treatment. Using differential display-polymerase chain reaction, several novel, hitherto unexpected lithium-regulated genes have been isolated, all of which would not have been predicted with the candidate gene approach. During the process of characterizing one of these novel genes, we have identified a cDNA clone, a homolog of human/mouse transmembrane-4-superfamily (also known as tetraspan) protein, CD151, the expression of which was significantly decreased in rat frontal cortex following chronic (five weeks) lithium treatment. The reduction of CD151 mRNA levels was also observed following chronic administration of carbamazepine and valproate. Conversely, the expression of CD151 was not altered by short-term (one week) lithium treatment and by chronic administration of the tricyclic antidepressant, imipramine, or the typical antipsychotic, haloperidol, further demonstrating time dependence and pharmacological specificity of this effect. Our studies, thus, indicate that CD151 may represent a therapeutically relevant target common to lithium and the anticonvulsant mood stabilizing drugs, carbamazepine and valproate.

[Neuropsychopharmacology 25:729-736, 2001] (C) 2001 American College of Neuropsychopharmacology. Published by Elsevier Science Inc.
KEY WORDS: Lithium; Carbamazepine; Valproate; Transmembrane-4-superfamily protein; CD151; Bipolar disorder

Although lithium is widely used in the treatment of acute mania and the prophylaxis for bipolar affective disorder, the cellular and molecular mechanisms underlying its therapeutic action remain unclear. How-

From the Section on Biochemical Psychiatry, Centre for Addiction and Mental Health, Clarke Site, Toronto, Ontario, Canada (LVH, MG, AW, JJW, PPL); Departments of Pharmacology (LVH, JJW, PPL), Psychiatry (JJW, PPL), and Institute of Medical Science (JJW), University of Toronto, Toronto, Ontario, Canada.

Address correspondence to: Dr. Peter P. Li, Laboratory of Cellular and Molecular Pathophysiology, Centre for Addiction and Mental Health, Clarke Site, 250 College Street, Toronto, Ontario, Canada, M5T 1R8.

Received November 27, 2000; revised April 6, 2001; accepted April 13, 2001.

Online publication: 4/17/01 at www.acnp.org/citations/ Npp041701105. ever, significant progress has been made over the past decade with cumulative evidence indicating that modulation of postreceptor signaling mechanisms in critical regions of the brain may be essential to the mood stabilizing properties of this agent (reviewed in Jope 1999; Li et al. 2000; Manji and Lenox 1999).

Many signal transduction cascades are known to induce long-term cellular responses through regulation of gene transcription. Moreover, the delayed onset of therapeutic action of lithium has led to the hypothesis that regulation of gene expression may be important for its mood stabilizing effects (Jope 1999; Li et al. 2000). In line with this hypothesis, several studies have demonstrated that chronic lithium treatment alters the expression of an array of genes, including $\mathrm{G}$ protein $\alpha$-subunits, adenylyl cyclase subtypes, neuropeptides (reviewed in Jope 1999; Li et al. 2000; Manji and Lenox 1999), proapoptotic and antiapoptotic proteins (Chen and Chuang 1999), and synaptic secretory vesicle proteins (Cordeiro 
et al. 2000). The modulatory effects of lithium on gene expression have been suggested to be mediated, at least in part, through the cAMP response element binding protein (CREB) or activator protein-1 (AP-1) transcriptional factor pathway (Ozaki and Chuang 1997; Asghari et al. 1998; Yuan et al. 1998). It is thus conceivable that other genes containing the consensus sequences for these transcription factors in their promoter region may also be the potential targets of lithium. Therefore, the identification of other lithium-regulated genes is important in better understanding the spectrum of cellular and molecular mechanisms that contribute to the therapeutic and/or side effects of this drug.

Using differential display-polymerase chain reaction (ddPCR), several novel lithium-regulated genes have been identified that would not otherwise have been considered using a candidate gene approach. These novel lithium-regulated targets included 2', 3'-cyclic nucleotide $3^{\prime}$-phosphodiesterase type II (Wang and Young 1996), polyomavirus enhancer-binding protein $2 \beta$ (Chen et al. 1999), nitrogen permease regulator 2 (Wang et al. 1999), aldolase A (Hua et al. 2000), and diphosphoinositol polyphosphate phosphohydrolase II (Hua et al. 2001). Unexpectedly, during the course of experiments amplifying the $5^{\prime}$ end of a putative lithium-regulated ddPCR fragment, we isolated another cDNA clone, a homolog of human/mouse transmembrane-4-superfamily (TM4SF) protein, CD151. The transcript levels of CD151 were significantly decreased in the rat frontal cortex after five weeks of lithium administration, an effect that was mimicked by chronic administration of carbamazepine or valproate. In contrast, short-term (1-week) lithium treatment and chronic administration of a tricyclic antidepressant imipramine or a typical antipsychotic haloperidol did not decrease CD151 mRNA levels, demonstrating time dependence and pharmacological specificity of this effect.

\section{METHODS}

\section{Chemicals}

Lithium carbonate, carbamazepine, sodium valproate, haloperidol $\mathrm{HCl}$, and imipramine $\mathrm{HCl}$ were obtained from Sigma Chemical Co. (St. Louis, MO). [ $\left.\alpha-{ }^{32} \mathrm{P}\right] \mathrm{dCTP}$ $(\sim 3000 \mathrm{Ci} / \mathrm{mmol})$ and $\left[\alpha-{ }^{33} \mathrm{P}\right] \mathrm{dATP}(\sim 2000 \mathrm{Ci} / \mathrm{mmol})$ were purchased from DuPont, New England Nuclear (Boston, MA). Cell ${ }^{+}$culture dishes were purchased from Sarstedt (St-Leonard, Quebec). All other reagents were acquired as molecular biological grade from either Sigma or Gibco-BRL (Burlington, ON).

\section{Animals and Treatments}

Male Wistar rats (275-300 g; Charles River, St. Constant, Quebec) were individually housed in a tempera- ture-controlled room $\left(21^{\circ} \mathrm{C} \pm 1^{\circ} \mathrm{C}\right)$ and maintained on a $12 \mathrm{hr}$ light/dark cycle with free access to food and water for at least a week before experiments. Animals were fed rat chow in pellet form containing lithium carbonate $(2.2 \mathrm{~g} / \mathrm{kg}$ diet; Bioserve, Frenchtown, NJ) for one or five weeks. Water and $2.6 \%$ saline were provided ad libitum to all animals. Rats receiving carbamazepine were fed with food pellets containing $0.25 \%$ carbamazepine for the first four days followed by $0.5 \%$ carbamazepine (Bioserve) for the next 31 days. In the valproate comparison group, animals were maintained on chow pellets containing $0.4 \%$ sodium valproate (Bioserve) for five weeks. Control groups of rats were fed with the regular rat chow for the indicated period. In other experiments, separate groups of rats received imipramine $(15 \mathrm{mg} / \mathrm{kg})$, haloperidol $(1 \mathrm{mg} / \mathrm{kg})$, or vehicle $(0.05 \%$ acetic acid in saline) once daily for five weeks via intraperitoneal injection and were killed $12 \mathrm{hr}$ after the last treatment. We have documented that with these methods of drug administration, drug-treated animals gained weight at a rate similar to those of control animals (Hua et al. 2000). Animals used in this study were cared for in strict accordance with guidelines of the Canadian Council on Animal Care, and the local Animal Care Committee approved the study.

At the end of the experiments, animals were decapitated. The brain was rapidly removed and gross brain regions were dissected over ice using natural lines of demarcation, and frozen on dry ice and stored at $-70^{\circ} \mathrm{C}$ until use. Blood samples were collected immediately after decapitation from the cervical trunk into heparinized test tubes. Plasma was separated by centrifugation $(900 \mathrm{~g}, 20 \mathrm{~min})$ for subsequent determination of drug concentrations (Hua et al. 2000).

\section{Cell Cultures}

Cultures of cerebral cortical neurons were prepared from fetal Wistar rats as previously described (Liu et al. 2000). Briefly, embryonic day 16-18 rat cerebral cortices were dissected and mechanically dissociated by trituration, plated onto Cell ${ }^{+}$culture dishes (Sarstedt), and maintained in modified Eagle's medium with $10 \%$ fetal calf serum. Cultures were grown at $37^{\circ} \mathrm{C}$ in $5 \% \mathrm{CO}_{2}$ for two weeks prior to RNA extraction.

\section{Rapid Amplification of cDNA Ends (RACE)}

5'-RACE was performed using the Marathon cDNA Amplification Kit (Clontech, Palo Alto, CA) following the manufacturer's instructions. Poly(A) ${ }^{+}$RNA was purified from $100 \mu \mathrm{g}$ of total RNA from rat frontal cortex using the FastTrack 2.0 Kit (Invitrogen, San Diego, CA), and reverse transcribed to cDNA. The cDNA was ligated to the Marathon cDNA adaptor (5'-ctaatacgactcactatagggctcgagcggccgccegggcaggt- $\left.3^{\prime}\right)$. The resulting ligated 
cDNA was subjected to amplification with adaptor primer (5'-ccatcctaatacgactcactatagggc- $\left.3^{\prime}\right)$ and ddPCR fragment-specific primer $\left(5^{\prime}\right.$-ccatttctttacgccgccacacaagtc- $\left.3^{\prime}\right)$. The amplified PCR products were purified from agarose gel, cloned into pGEM-T vector, and sequenced on both strands by the dye-terminator sequencing kit followed by analysis on an ABI Model Prism 377 DNA sequencer (PE Applied System, Foster City, CA).

\section{Northern Blot Analysis}

Heat-denatured total RNA (10 $\mu \mathrm{g} /$ lane) from individual control and experimental animals were size-fractionated on $1 \%$ agarose $/ 0.66 \mathrm{M}$ formaldehyde gels and transferred onto GeneScreen Plus membranes (New England Nuclear, Boston, MA) as previously described (Li et al. 1993). The membranes were prehybridized at $42^{\circ} \mathrm{C}$ for 2-4 hr in $5 \times$ SSPE, $50 \%$ formamide, $5 \times$ Denhardt's solution, $1 \%$ sodium dodecyl sulfate, $10 \%$ dextran sulfate, and $200 \mu \mathrm{g} / \mathrm{ml}$ denatured salmon sperm DNA, and subsequently hybridized in the same buffer containing a ${ }^{32} \mathrm{P}-$ labeled, random-primed cDNA probe $\left(1 \times 10^{6} \mathrm{cpm} / \mathrm{ml}\right)$ prepared from a gel-purified insert. After progressively stringency washing, hybridization signals were obtained by exposing the membranes to phosphoscreens and quantified with the Storm and ImageQuant software (Molecular Dynamics). The blots were stripped and rehybridized with ${ }^{32} \mathrm{P}$-labeled rat cyclophilin cDNA to normalize for RNA loading and transfer.

\section{Statistical Analysis}

Statistical analysis of the data was performed using either one-way ANOVA, followed by post-hoc Tukey's HSD test to assess differences between cell means or two-tailed unpaired Student's t-test. $P$-values $<0.05$ were considered statistically significant. Data were expressed as mean \pm SEM.

\section{RESULTS}

\section{PCR Amplification of a Novel cDNA and Regulation by Mood Stabilizing Drugs}

5'-RACE was used to construct a full-length cDNA of a candidate lithium-regulated ddPCR fragment, LRG2. This process resulted in the amplification of three PCR fragments, two of which $(5 R 1,5 R 2)$ were later proved to be partial clones of diphosphoinositol polyphosphate phosphohydrolase II (Hua et al. 2001). In an initial characterization of the other PCR fragment, designated 5R3, the tissue distribution of its corresponding mRNA was examined. Northern blot analysis of a variety of rat tissues revealed three transcripts of $\sim 3.0, \sim 2.0$, and $\sim 1.6$ $\mathrm{kb}$ (Figure 1). With the exception of cerebellum where the $2.0 \mathrm{~kb}$ species is predominant, the relative abundance of the $5 \mathrm{R} 3$ transcripts in all brain regions examined followed a conserved rank order of $1.6>2.0>3.0$ $\mathrm{kb}$ species. The $5 \mathrm{R} 3 \mathrm{mRNA}$ signals were also detectable in primary cultures of rat cerebral cortical neurons. In the peripheral tissues, the strongest signal was observed in the lung, heart and kidney, followed by liver and spleen.

Figure 2A shows that the abundance of $1.6 \mathrm{~kb}$ species of $5 R 3$ mRNA was significantly decreased by $38 \%$ in the frontal cortex following chronic lithium treatment $(\mathrm{t}=$ $2.66, \mathrm{df}=14, p=.02$ ). No significant effect of chronic administration of lithium on the levels of the $2.0 \mathrm{~kb}$ species was observed $(\mathrm{t}=0.51, \mathrm{df}=14, p=.87)$, and the $3.0 \mathrm{~kb}$ species was too weak to be analyzed. In contrast, short-term (1-week) lithium treatment did not significantly affect the levels of either $1.6 \mathrm{~kb}(\mathrm{t}=1.01, \mathrm{df}=10$, $p=.33$ ) (Figure $2 \mathrm{~A}$ ) or $2.0 \mathrm{~kb}$ mRNA species of $5 \mathrm{R} 3(\mathrm{t}=$ $0.84, \mathrm{df}=10, p=.42$ ).

To determine whether the downregulation of the 1.6 $\mathrm{kb}$ species of $5 \mathrm{R} 3$ was unique to lithium, the effects of chronic administration of anticonvulsant mood stabilizers, carbamazepine and valproate, on the levels of this transcript were investigated (Figure 2B). There was a significant main effect of drug on 5R3 mRNA levels $(\mathrm{F}(3,23)=5.89, p=.004)$. Post-hoc analysis revealed that the levels of $5 \mathrm{R} 3 \mathrm{mRNA}$ were significantly reduced in rat frontal cortex following chronic administration of lithium, carbamazepine or valproate (Tukey's test; $p=$ $.008, .008$, and .017 , respectively). Note that the magnitude of decrease in CD151 mRNA by carbamazepine $(57 \%)$ and valproate $(52 \%)$ was almost identical to that observed for lithium (57\%). In contrast, chronic administration of imipramine or haloperidol did not affect the levels of $5 \mathrm{R} 3 \mathrm{mRNA}$ in the frontal cortex $(\mathrm{F}(2,18)=0.41$, $p=.67)$.

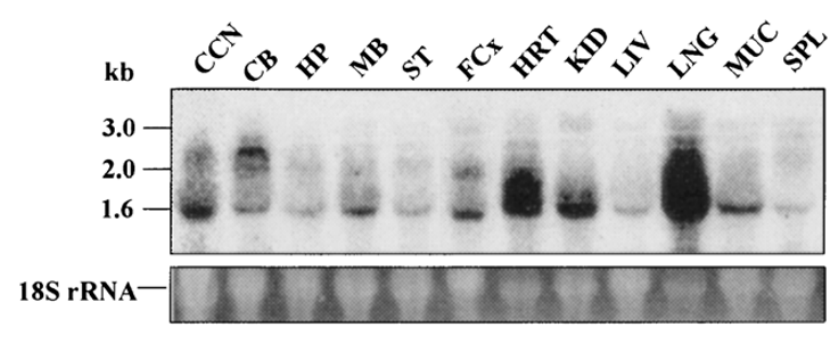

Figure 1. Northern blot analysis of 5R3 mRNA expression from various rat tissues. Each lane contained $10 \mu \mathrm{g}$ total RNA. The top panel shows a Northern blot hybridized with radiolabeled 5R3 cDNA as described in "Methods". Three gene transcripts of $1.6 \mathrm{~kb}, 2.0 \mathrm{~kb}$, and $3.0 \mathrm{~kb}$ are detected. The bottom panel shows the same gel before electrophoresis and staining with ethidium bromide to reveal the levels of $18 \mathrm{~S}$ ribosomal RNA. Abbreviations: CCN, cerebral cortical neurons; $\mathrm{CB}$, cerebellum; $\mathrm{HP}$, hippocampus; $\mathrm{MB}$, midbrain; ST, striatum, FCx, frontal cortex; HRT, heart; KID, kidney; LIV, liver; LNG, lung; MUC, muscle; SPL, spleen. 

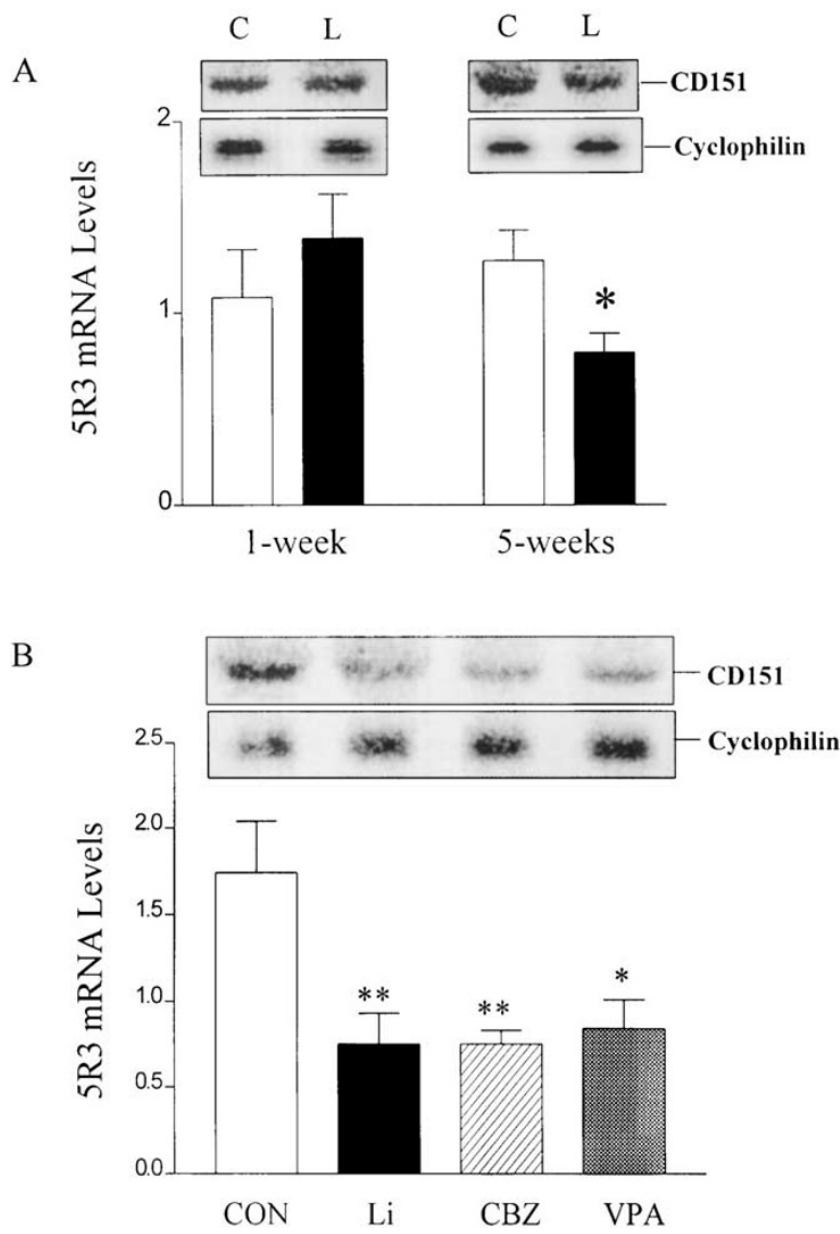

Figure 2. Effect of administration of mood stabilizing drugs on the 5R3 transcript levels in rat frontal cortex. (A) Effect of short-term and chronic lithium administration on the expression of 5R3 mRNA. Rats were fed with $0.22 \%$ lithium carbonate (filled columns) or regular rat chow (open columns) for one or five weeks. Representative mRNA message for control (C) and lithium (L) are shown in the top panels. Plasma lithium concentrations after one or five weeks of lithium treatment were $0.53 \pm 0.07$ and $0.76 \pm 0.04 \mathrm{mM}$, respectively. ${ }^{*} p=.02$ compared with control animals (Student's t-test). (B) Effect of chronic lithium (Li), carbamazepine (CBZ), and valproate (VPA) administration on the expression of 5R3 mRNA. Rats were fed with regular chow (CON), or chows containing Li, CBZ, or VPA for five weeks as described in "Methods". The plasma drug concentrations were as follows: lithium, $0.94 \pm 0.08 \mathrm{mM}$; CBZ, $13.2 \pm 3.8$ $\mu \mathrm{M}$; VPA, $18.5 \pm 4.6 \mu \mathrm{M}$. Levels of $5 \mathrm{R} 3 \mathrm{mRNA}$ were determined by northern blot analysis of the $1.6 \mathrm{~kb}$ species in the frontal cortex and normalized against cyclophilin mRNA signals. The results are expressed as the mean \pm SEM for six to eight animals. ${ }^{*} p=.017{ }^{* *} p=.008$ compared with control animals (Tukey's test).

\section{Characterization of Clone 5R3}

Clone 5R3 contains an insert of 1668 base pairs (bp) corresponding to the size of smallest transcript on northern blot (Figure 1). Sequence analysis reveals a 759-bp open reading frame encoding a protein of 253 amino acids with a calculated molecular mass of $28.4 \mathrm{kDa}$ (Figure 3 ). The presumed initiation codon lies within the Kozak consensus sequence, $39 \mathrm{bp}$ downstream from an inframe stop codon. Examination of the 5'-untranslated region (UTR) showed it to be highly GC rich (60\%) with eighteen CpG doublets. The 3'-UTR contained a putative polyadenylation signal, AATAAA, which is located 12 bp upstream from the poly $\mathrm{A}^{+}$tail. Hydropathy analysis of the deduced amino acid sequence indicates the presence of four hydrophobic regions, predicted to represent putative transmembrane domains, and both the aminoand carboxyl termini located intracellularly. The predicted amino acid sequence reveals a single TM4SF signature sequence (residues 68-90) overlapped with a leucine zipper (LZ)-like motif (residues 89-110). One consensus site for N-linked glycosylation (residue 159) is present in a region that may be a large extracellular loop (EC2). Potential sites for phosphorylation by protein kinase $C$ are present on predicted intracellular domain and carboxyl terminus (residues 82 and 247). There is also one possible site for phosphorylation by protein kinase A on the amino terminus (residue 10).

Comparison of the cDNA and predicted amino acid sequences with those in the GenBank database demonstrated sequence similarity between clone $5 \mathrm{R} 3$ and members of the TM4SF, particularly with a $96 \%$ amino acid homology with mouse CD151 (Hasegawa et al. 1997) and $92 \%$ with human CD151 (Fitter et al. 1995). Within the TM4SF motif, the amino acid sequence identity between clone 5R3 and mouse and human CD151 was $100 \%$ and $95 \%$, respectively (Figure 3). Of note, the $5^{\prime}$ and $3^{\prime}$ UTR of clone 5R3 were highly similar to the mouse CD151 cDNA (Hasegawa et al. 1997), but were different from those of human CD151 (Fitter et al. 1995). On the basis of sequence analysis, it was concluded that this clone is a true orthologue of the human/mouse CD151, thus designated as rCD151.

\section{DISCUSSION}

The results of this study identified CD151 as a novel target gene that is regulated by lithium treatment. Regulation of CD151 expression was observed following chronic, but not short-term, lithium administration, consistent with the delayed onset of its therapeutic action. Significantly lower expression of this transcript was also observed in response to chronic carbamazepine or valproate treatment. However, chronic administration of the typical antipsychotic haloperidol and the tricyclic antidepressant imipramine did not significantly influence the levels of CD151 mRNA. These results suggest that CD151 is a potential common intracellular target that may contribute to the cellular and 
TM 1

$\begin{array}{llllll}\text { Rat } & \text { CD151 } & \text { MGEFNEKKATCGTVCLKYI LFTYNCCFWLAGLAVMAVGIWTLALKSDYISLLASSTYLAT } & 60 \\ \text { Mouse } & \text { CD151 } & \text { MGEFNEKKATCGTVCLKYI LFTYNCCFWLAGLAVMAVGIWTLALKSDYISLLASSTYLAT } & 60 \\ \text { Human } & \text { CD151 } & \text { MGEFNEKKTTCGTVCLKYI LFTYNCCFWLAGLAVMAVGIWTLALKSDYISLLASGTYLAT } & 60\end{array}$

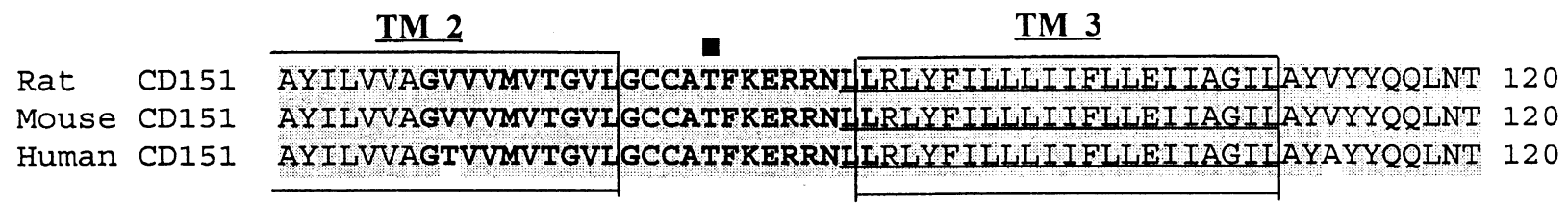

Rat CD151 ELKENLKDTMIKRYHQSGHEGVTNAVDKLQQEFHCCGSNNSRDWRDSEWIRSGEADSRVV 180 Mouse CD151 ELKENLKDTMVKRYHQSGHEGVSSAVDKLQQEFHCCGSNNSQDWQDSEWIRSGEADSRVV 180 Human CD151 ELKENLKDTMTKRYHQSGHEAVTSAVDQLQQEFHCCGSNNSQDWRDSEWIRSQEAGGRVV 180

\section{TM 4}

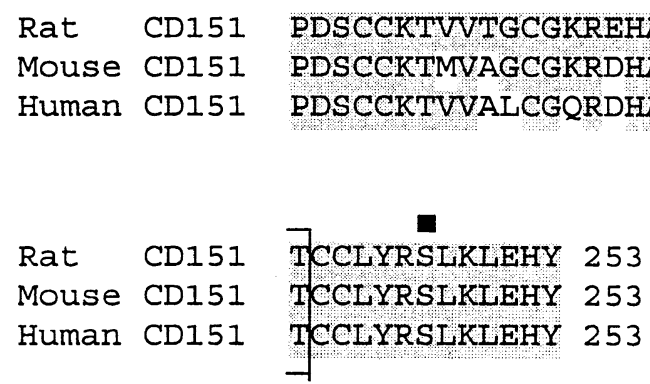

Figure 3. Alignment of deduced amino acid sequences of the rat CD151 with those of the human (Accession \# NP004348) and mouse CD151 (Accession \# NP033972). Single-letter amino acid code is used and identical residues among the three sequences are shaded. Putative hydrophobic (membrane-spanning) domains are boxed. The signature for TM4SF is bolded and a potential leucine zipper motif is underlined. Postulated N-linked glycosylation site $(\bullet)$, potential sites for protein kinase C ( $\square)$ and protein kinase A $(\square)$ are indicated. The complete sequence of the rat CD151 has been submitted to GenBank (accession no. AF192547).

molecular changes leading to therapeutic response to these mood-stabilizing drugs.

Although initially identified as a platelet/leukocyte surface glycoprotein, CD151 is expressed in a wide variety of tissues and cell types including megakaryoctes, endothelial cells, and myocytes (Fitter et al. 1995, 1998; Hasegawa et al. 1997). We present here the first observations on the regional distribution of CD151 transcripts in rat brain, which is in marked contrast to that reported in earlier studies which showed very low level of expression in mouse and human brain (Sincock et al. 1997; Hasegawa et al. 1997). The presence of CD151 mRNA in rat brain is unlikely due only to expression in the vascular endothelial compartment because the transcripts are also present at high levels in cultured cortical neurons. Moreover, there is also evidence of CD151 expression in the developing rat brain, PC12 cells (L. Ashman, personal communication), and human neuronal NT2N cells (Stipp and Hemler 2000), further supporting the idea that CD151 is also neuronally expressed.
The presence of three mRNA species in various rat tissues is peculiar, since human and mouse CD151 have been shown to express only one single transcript (Fitter et al. 1995; Hasegawa et al. 1997). It is likely that we isolated the cDNA corresponding to the $1.6 \mathrm{~kb}$ form of rCD151. Southern analyses of rat brain genomic DNA digested with the restriction enzymes Pst I, Hind III, EcoR I, or BamH I, revealed a single band indicating the absence of other closely related genes (data not shown). Another possibility considered was that the different species of CD151 in rat tissues could result from the use of different transcriptional start sites or of different polyadenylation signals. Subsequent screening of a rat brain library by PCR, however, only identified one positive clone with the same nucleotide sequence as clone 5R3 (data not shown). Further analysis of the genomic structure of rCD151 is necessary to determine the origin and nature of the different species of CD151 transcripts.

One intriguing observation from the analysis of the deduced amino acid sequence of CD151 is the presence 
of a LZ-like motif within the third putative transmembrane domain. LZ motifs mediate dimer formation via a coiled-coil arrangement of parallel $\alpha$-helices, and are found in many eukaryotic transcription factors (Landschulz et al. 1988). Although it is well established that many cell surface receptors mediate their action as dimers (Hebert and Bouvier 1998), it remains to be determined whether CD151 exists and functions as homodimer.

Although the precise function of CD151 in the brain has not yet been defined, studies in haemopoietic cell lines have indicated an important role of CD151 in an array of fundamental cellular processes, including cell motility (Yauch et al. 1998), cell adhesion (Fitter et al. 1999), angiogenesis, and vesicular transport of integrins (Sincock et al. 1999). In addition, CD151 has been shown to serve as an adaptor or scaffolding protein to attach integrin subunits to other intracellular signaling molecules, such as phosphatidylinositol 4-kinase (PI 4-K) (Yauch et al. 1998) and $\alpha$ - and $\beta$-isozymes of protein kinase C (PKC) (Hemler 1998). Indeed, over $90 \%$ of PI 4-kinase activity was associated with the CD151-integrin complex in HT1080 and A431 cell lines (Yauch et al. 1998). The integrin/CD151/PI 4-K complex could therefore provide a molecular framework for localized production of phosphatidylinositol-4-phosphate (PIP), and phosphatidylinositol-4, 5-bisphosphate $\left(\mathrm{PIP}_{2}\right)($ Hemler 1998). Similarly, the integrin/CD151/PKC complex defines a role for CD151 in the recruitment of activated PKC isozymes to their substrates, i.e., integrin, in discrete subcellular compartments (Hemler 1998). These observations, therefore, suggest a potential physiological role of CD151 in the regulation of phosphoinositide second messenger transduction processes.

The downregulation of CD151 mRNA expression following chronic treatment with lithium, carbamazepine, and valproate may have therapeutic implications, inasmuch as an abnormality in phosphoinositide signaling pathways has been implicated in the pathophysiology of bipolar affective disorder ( $\mathrm{Li}$ et al. 2000; Warsh and Li 2000). For example, increased platelet membrane PKC activity and $\mathrm{PIP}_{2}$ levels have been reported in drug-free manic bipolar patients, alterations which subsequently normalized with lithium treatment (Brown et al. 1993; Friedman et al. 1993; Soares et al. 2000a). In addition, the platelet levels of $\mathrm{PIP}_{2}$ and the PKC- $\alpha$ isozyme were significantly reduced in lithiumtreated bipolar patients compared with healthy control subjects (Soares et al. 2000b). Similarly, chronic administration of lithium or valproate decreased the levels of membrane PKC $\alpha$ and $\epsilon$ isozymes in rat frontal cortex and hippocampus, immortalized hippocampal cells and PC12 cells (reviewed in Manji and Lenox 1999). These results together with the findings that CD151 acts as an anchoring protein for PI 4-K and activated PKC $\alpha$ (Hemler 1998; Yauch et al. 1998), raise an interesting possibility that these mood stabilizers, lithium in particular, may normalize the hyperfunctional phosphoinositide signaling pathways implicated in bipolar disorder, in part through down-regulation of CD151 expression.

While CD151 mRNA levels in the frontal cortex were decreased by lithium treatment that achieved therapeutically relevant serum concentrations $(\sim 0.7$ to $1.0 \mathrm{mM})$, the reductions in mRNA levels in carbamazepine and valproate treated animals occurred at low $(\sim 13 \mu \mathrm{M})$ or subtherapeutic $(\sim 20 \mu \mathrm{M})$ levels compared to the accepted concentration ranges for therapeutic response to these drugs in bipolar patients (carbamazepine: 16-50 $\mu \mathrm{M}$; valproate: $350-850 \mu \mathrm{M}$ ) (Joffe and Calabrese 1994). The low plasma carbamazepine concentrations were comparable to the values obtained by other investigators using a similar dosing regimen (Marangos et al. 1985; Lee et al. 2000). These low levels are likely a result of differences between the rat and human in the metabolism of these drugs. In humans, carbamazepine 10,11epoxide is a major active metabolite of carbamazepine, but its level is only approximately $20 \%$ of that of the parent compound. Conversely, the levels of carbamazepine 10,11-epoxide are about four-fold higher than carbamazepine in rats (Marangos et al. 1985).

Using a similar dosing regimen, a plasma concentration of $39 \mu \mathrm{M}$ of carbamazepine 10,11-epoxide was previously reported in rats (Kofman et al. 1998). Thus the combined carbamazepine and 10,11-epoxide levels in plasma of rats might approximate those attained clinically in humans. In the case of valproate, the low plasma levels likely reflect the short half-life of this drug in rats (approximately $90 \mathrm{~min}$ ), which metabolize valproate an order of magnitude faster than humans (Dickinson et al. 1979). It is also possible that the levels of valproate are higher in the brain of the rat than the plasma data suggest. Nevertheless, these results indicate that significant pharmacological effects can occur even at plasma carbamazepine and/or valproate levels that border the accepted therapeutic range for bipolar disorder. This is further supported by the observations of Mark et al. (1995) who showed that carbamazepine and valproate exerted significant neuroprotective effects against cytotoxic insults in cultured hippocampal neurons at concentrations below the range used in treatment of epilepsy or bipolar patients. Moreover, the down-regulation of CD151 expression appears to be pharmacologically specific to this class of drugs, because chronic administration of at least the typical antipsychotic, haloperidol, and the tricyclic antidepressant, imipramine, did not influence the expression of CD151. These results suggest that downregulation of CD151 expression may represent a therapeutically relevant compensatory response common to these mood-stabilizing drugs.

The mechanism(s) underlying the decrease in CD151 expression by lithium, carbamazepine, and valproate is 
largely unknown, since the factors regulating the expression of CD151 are at present poorly understood. It is unlikely that the reduction in CD151 expression is attributable to the weight loss commonly observed in rats during chronic administration of these mood stabilizers (Baptista et al. 1995; Lee et al. 2000), as there were no significant differences in weight gain between control and drug-treated animals during the treatment period (Hua et al. 2000). Among possible mechanisms that might account for the reduced CD151 expression, altered RNA metabolism through various nuclear events, including rate of transcription, mRNA export, or mRNA degradation, merit further consideration. In this regard, several lines of evidence indicate that these mood stabilizers modulate c-fos mRNA levels (Miller and Mathe, 1997; Lee et al. 2000), and DNA binding activity and/or protein levels of various transcription factors, such as CREB and AP-1 (Ozaki and Chuang 1997; Asghari et al. 1998; Yuan et al. 1998). These could potentially be involved in the regulation of CD151 expression. However, further studies are necessary to elucidate the specific mechanism that accounts for the decreased expression of CD151 in response to these mood stabilizers and to determine whether the reduced CD151 expression is translated into decreased activity and/or protein levels.

Recent evidence indicates that chronic administration of lithium alters the expression of a subset of genes involved in regulating inositol phosphate metabolism and/or $\mathrm{InsP}_{3}$ /PKC signaling, either directly or indirectly. This includes inositol monophosphatase (Shamir et al. 1998), diphosphoinositol polyphosphate phosphohydrolase II (Hua et al. 2001), sodium/myo-inositol cotransporter (Lubrich and van Calker 1999), aldolase A (Hua et al. 2000) and C isozymes (Hua and Li, unpublished), prolyl oligopeptidase (Williams et al. 1999), and CD151 (present study). Such a cluster of changes is unlikely a chance event. A similar phenomenon also occurs in the cAMP signaling pathway, in which the ex-

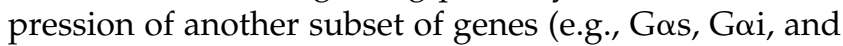
subtypes of adenylyl cyclase) is modulated following chronic lithium treatment (Li et al. 2000). The effect of lithium to induce changes in such a spectrum of genes within a signaling cascade may represent the sequential, compensatory readjustment to normalize the putative disturbances of the intracellular signaling cascade in the disease process. Alternatively, such alterations may reflect adaptive mechanisms operative within or between different signaling pathways to maintain intracellular signaling homeostasis in response to lithium treatment. Nevertheless, these observations clearly support the potential therapeutic relevance of this effect of lithium to regulate the expression of a distinctive set of genes involved in signaling pathways known to be dysregulated in bipolar disorder ( $\mathrm{Li}$ et al. 2000; Warsh and Li 2000).

\section{ACKNOWLEDGMENTS}

This work was partially supported by grants (to P.P.L.) from the Ontario Mental Health Foundation and the National Alliance for Research in Schizophrenia and Affective Disorders (NARSAD).

\section{REFERENCES}

Asghari V, Wang JF, Reiach JS, Young LT (1998): Differential effects of mood stabilizers on Fos/Jun proteins and AP-1 DNA binding activity in human neuroblastoma SH-SY5Y cells. Mol Brain Res 58:95-102

Baptista T, Teneud L, Contreras Q, Alastre T, Burguera JL, de Burguera M, de Baptista E, Weiss S, Hernandez L (1995): Lithium and body weight gain. Pharmacopsychiatry 28:35-44

Brown AS, Mallinger AG, Renbaum LC (1993): Elevated platelet membrane phosphatidylinositol-4,5-bisphosphate in bipolar mania. Am J Psychiatry 150:1252-1254

Chen G, Zeng WZ, Yuan PX, Huang LD, Jiang YM, Zhao $\mathrm{ZH}$, Manji HK (1999): The mood stabilizing agents lithium and valproate robustly increase the levels of the neuroprotective protein bcl-2 in the CNS. J Neurochem 72:879-882

Chen R-W, Chuang D-M (1999): Long-term lithium treatment suppresses p53 and Bax expression but increases Bcl-2 expression: A prominent role in neuroprotection against excitotoxicity. J Biol Chem 274:6039-6042

Cordeiro ML, Umbach JA, Gundersen CB (2000): Lithium ions up-regulate mRNAs encoding dense-core vesicle proteins in nerve growth factor-differentiated PC12 cells. J Neurochem 75:2622-2625

Dickinson DG, Harland RC, Ilias AM, Rodgers RM, Kaufman SN, Lynn RK, Gerber N (1979): Disposition of valproic acid in the rat: Dose-dependent metabolism, distribution, enterohepatic recirculation and choleretic effect. J Pharmacol Exp Ther 211:583-595

Fitter S, Tetaz TJ, Berndt MC, Ashman KL (1995): Molecular cloning of cDNA encoding a novel platelet-endothelial cell tetra-span antigen, PETA-3. Blood 86:1348-1355

Fitter S, Seldin MF, Ashman LK (1998): Characterisation of the mouse homologue of CD151 (PETA-3/SFA-1); genomic structure, chromosomal localisation and identification of 2 novel splice forms. Biochim Biophys Acta 1398:75-85

Fitter S, Sincock PM, Jolliffe CN, Ashman LK (1999): Transmembrane 4 superfamily protein CD151 (PETA-3) associates with $3 a ́ 1$ and IIbá3 integrins in haemopoietic cell lines and modulates cell-cell adhesion. Biochem J 338:61-70

Friedman E, Hoau YW, Levinson D, Connell TA, Singh H (1993): Altered platelet protein kinase C activity in bipolar affective disorder, manic episode. Biol Psychiatry 33:520-525

Hasegawa $H$, Watanabe $H$, Nomura T, Utsunomiya $Y$, Yanagisawa K, Fujita S (1997): Molecular cloning and expression of mouse homologue of SFA-1/PETA-3 (CD151), a member of the transmembrane 4 superfamily. Biochim Biophys Acta 1353:125-130 
Hebert TE, Bouvier M (1998): Structural and functional aspects of $\mathrm{G}$ protein-coupled receptor oligomerization. Biochem Cell Biol 76:1-11

Hemler ME (1998): Integrin associated proteins. Curr Opin Cell Biol 5:578-585

Hua LV, Green M, Warsh JJ, Li PP (2000): Lithium regulation of aldolase A expression in rat frontal cortex: Identification by differential display. Biol Psychiatry 48:58-64

Hua LV, Green M, Warsh JJ, Li PP (2001): Molecular cloning of a novel isoform of diphosphoinositol polyphosphate phosphohydrolase: A potential target of lithium therapy. Neuropsychopharmacol, 24:640-651

Joffe RT, Calabrese JR (1994): Anticonvulsants in Mood Disorders. New York, Marcel Dekker, Inc

Jope RS (1999): Anti-bipolar therapy: Mechanism of action of lithium. Mol Psychiatry 4:117-128

Kofman O, Li PP, Warsh JJ (1998): Lithium, but not carbamazepine, potentiates hyperactivity induced by intraaccumbens cholera toxin. Pharmacol Biochem Behav 59:191-200

Landschulz WH, Johnson PF, McKnight SL (1988): The leucine zipper: A hypothetical structure common to a new class of DNA binding proteins. Science 240:1759-1764

Lee Y, Hamamura T, Ohashi K, Miki M, Fujiwara Y, Kuroda S (2000): Carbamazepine suppresses methamphetamine-induced fos expression in a regionally specific manner in the rat brain: Possible neural substrates responsible for antimanic effects of mood stabilizers. Neuropsychopharmacology 22:530-537

Li PP, Young LT, Tam YK, Warsh JJ (1993): Effects of chronic lithium and carbamazepine treatment of G-protein subunit expression in rat cerebral cortex. Biol Psychiatry 34:162-170

Li PP, Andreopoulos S, Warsh JJ (2000): Signal transduction abnormalities in bipolar affective disorder. In Reith MEA (ed), Cerebral Signal Transduction: From First to Fourth Messengers. Totowa, NJ, Humana Press, pp 283-309

Liu F, Wan Q, Pristupa ZB, Yu XM, Wang YT, Niznik HB (2000): Direct protein-protein coupling enables crosstalk between dopamine D5 and gamma-aminobutyric acid A receptors. Nature 403:274-280

Lubrich B, van Calker D (1999): Inhibition of the high affinity myo-inositol transport system: A common mechanism of action of antibipolar drugs? Neuropsychopharmacology 21:519-529

Manji HK, Lenox RH (1999): Protein kinase C signaling in the brain: molecular transduction of mood stabilization in the treatment of manic-depressive illness. Biol Psychiatry 46:1328-1351

Marangos PJ, Weiss SRB, Montgomery P, Patel J, Narang PK, Cappabianca AM, Post RM (1985): Chronic carbamazepine treatment increases brain adenosine receptors. Epilepsia 26:493-498

Mark RJ, Ashford JW, Goodman Y, Mattson MP (1995): Anticonvulsants attenuate amyloid beta-peptide neurotoxicity, $\mathrm{Ca}^{2+}$ deregulation, and cytoskeletal pathology. Neurobiol Aging 16:187-198

Miller JC, Mathe AA (1997): Basal and stimulated C-fos
mRNA expression in the rat brain: Effect of chronic dietary lithium. Neuropsychopharmacology 16:408-418

Ozaki N, Chuang DM (1997): Lithium increases transcription factor binding to AP-1 and cyclic AMP-responsive element in cultured neurons and rat brain. J Neurochem 69:2336-2344

Shamir A, Ebstein RP, Nemanov L, Zohar A, Belmaker RH, Agam G (1998): Inositol monophosphatase in immortalized lymphoblastoid cell lines indicates susceptibility to bipolar disorder and response to lithium therapy. Mol Psychiatry 3:481-482

Sincock PM, Mayrhofer G, Ashman LK (1997): Localization of the transmembrane 4 superfamily (TM4SF) member PETA-3 (CD151) in normal human tissues: comparison with CD9, CD63, and alpha5beta1 integrin. J Histochem Cytochem 45:515-525

Sincock PM, Fitter S, Parton RG, Berndt MC, Gamble JR, Ashman LK (1999): PETA-3/CD151, a member of the transmembrane 4 superfamily, is localised to the plasma membrane and endocytic system of endothelial cells, associates with multiple integrins and modulates cell function. J Cell Sci 112:833-844

Soares JC, Mallinger AG, Dippold CS, Forster Wells K, Frank E, Kupfer DJ (2000a): Effects of lithium on platelet membrane phosphoinositides in bipolar disorder patients: A pilot study. Psychopharmacology 149:12-16

Soares JC, Chen G, Dippold CS, Wells KF, Frank E, Kupfer DJ, Manji HK, Mallinger AG (2000b): Concurrent measures of protein kinase $\mathrm{C}$ and phosphoinositides in lithium-treated bipolar patients and healthy individuals: A preliminary study. Psychiatry Res 95:109-118

Stipp CS, Hemler ME (2000): Transmembrane-4-superfamily proteins CD151 and CD81 associate with $\alpha_{3} \beta_{1}$ integrin, and selectively contribute to $\alpha_{3} \beta_{1}$-dependent neurite outgrowth. J Cell Sci 113: 1871-1882

Wang JF, Young LT (1996): Differential display PCR reveals increased expression of 2'3'-cyclic nucleotide 3'-phosphodiesterase by lithium. FEBS Lett 386:225-229

Wang JF, Chen B, Young LT (1999): Identification of a novel lithium regulated gene in rat brain. Mol Brain Res 70:66-73

Warsh JJ, Li PP (2000): Postmortem studies in bipolar disorder. In Soares JC, Gershon S (eds), Basic Mechanisms and Therapeutic Implications of Bipolar Disorder. New York, Marcel Dekker, Inc, pp 201-226

Williams RS, Eames M, Ryves WJ, Viggars J, Harwood AJ (1999): Loss of a prolyl oligopeptidase confers resistance to lithium by elevation of inositol $(1,4,5)$ trisphosphate. EMBO J 18:2734-2745

Yauch RL, Berditchevski F, Harler MB, Reichner J, Hemler ME (1998): Highly stoichiometric, stable, and specific association of integrin 3á1 with CD151 provides a major link to phosphatidylinositol 4- kinase, and may regulate cell migration. Mol Biol Cell 9:2751-2765

Yuan PX, Chen G, Huang LD, Manji HK (1998): Lithium stimulates gene expression through the AP-1 transcription factor pathway. Mol Brain Res 58:225-230 